\title{
ENTROPY GENERATION IN MHD FLOW OF VISCOELASTIC NANOFLUIDS WITH HOMOGENEOUS-HETEROGENEOUS REACTION, PARTIAL SLIP AND NONLINEAR THERMAL RADIATION
}

\author{
M. Almakki ${ }^{1}$, H. Mondal ${ }^{*}$, P. Sibanda ${ }^{3}$
}

\begin{abstract}
We investigate the combined effects of homogeneous and heterogeneous reactions in the boundary layer flow of a viscoelastic nanofluid over a stretching sheet with nonlinear thermal radiation. The incompressible fluid is electrically conducting with an applied a transverse magnetic field. The conservation equations are solved using the spectral quasi-linearization method. This analysis is carried out in order to enhance the system performance, with the source of entropy generation and the impact of Bejan number on viscoelastic nanofluid due to a partial slip in homogeneous and heterogeneous reactions flow using the spectral quasi-linearization method. Various fluid parameters of interest such as entropy generation, Bejan number, fluid velocity, shear stress heat and mass transfer rates are studied quantitatively, and their behaviors are depicted graphically. A comparison of the entropy generation due to the heat transfer and the fluid friction is made with the help of the Bejan number. Among the findings reported in this study is that the entropy generation has a significant impact in controlling the rate of heat transfer in the boundary layer region.
\end{abstract}

\section{Keywords: Nanofluids, Viscoelastic Fluid, Homogeneous_Heterogeneous Reactions, Nonlinear Thermal Radiation.}

\section{INTRODUCTION}

In recent years, nanofluids have attracted a considerable amount of interest due to their novel properties that make them potentially useful in a number of industrial applications including transportation, power generation, micro manufacturing, thermal therapy for cancer treatment, chemical and metallurgical sectors, heating, cooling, ventilation, and air-conditioning. The term nanofluid is used to refer to a solid-liquid mixture with a continuous phase, Choi [1]. Nanofluids are used in many areas including oil extraction, cancer therapy and safer surgery by cooling. The twodimensional boundary layer flow in porous media caused by a stretching surface has received considerable attention because such flows arise in many applications such as in paper industry, aerodynamic extrusion of plastic sheets, hot rolling, wire drawing, glass-fiber production and the manufacture of polymer and rubber sheets, Fisher [2]. Makinde et al. [3] investigated nanofluid flow over a linear stretching sheet with thermophoresis and particle Brownian motion. The Brownian motion and thermophoresis lead to an increase in the rate of heat transfer. However, the opposite was observed in the case of the rate of mass transfer.

The effect of an applied magnetic field on nanofluids has substantial applications in chemistry, physics and engineering. These include cooling of continuous filaments, in the process of drawing, annealing and thinning of copper wire. Drawing such strips through an electrically conducting fluid subject to a magnetic field can control the rate of cooling and stretching, thereby furthering the desired characteristics of the final product. Such an application of a linearly stretching sheet of incompressible viscous flow of MHD was discussed by Chamka [4].

It is a well-established fact that all bodies emit thermal radiation when their temperature is greater than zero. The greater the bodies temperature, the greater the thermal radiation. As a result of thermal radiation, when two bodies come in contact with each other, the hotter one transmits heat to the less hot one until the reach the same temperature. The previously stated sentences on thermal radiation is an informed statement of Prevostis Theory of thermal radiation which is regarded as the corner of motion theory of thermal radiation; please refer to Putley [5] for elaborate details. Heat transfer and viscous dissipation of MHD nanaofluid flow through a permeable stretching/shrinking sheet was investigated by Sandeep et al. [6]. Raju et al. [7] was scrutinized the influence of the thermal radiation on ferrofluid across a flat plate within slip velocity and aligned magnetic field. The effects of thermal radiation in presence of MHD of nanofluid flow throughout two horizontal rotating plates was studied by Mohsen et al. [8]. They pointed out that Nusselt number has remarkable relation with thermal radiation. The common approach prior studies $[6,7,8]$ to nonlinear temperature is to simplify it using Taylor serious up to a certain order and accept a truncated error. Consequently, the complexity of the analysis of a thermal radiation model reduces substantially. The linear approximation of the nonlinear temperature may lead to inconsistency with realistic practical applications in industry and engineering as the thermal radiation, which is a function of temperature, may be far from being linear in reality.

\footnotetext{
${ }^{1,3}$ School of Mathematics, Statistics\&Computer Science, University of KwaZulu-Natal, Scottsvile, Pietermaritzburg, South Africa ${ }^{2}$ Department of Mathematics, Brainware University, Barasat, West Bengal, Kolkata, India

Email Address:m.almakki1977@gmail.com, hiranmoymondal@yahoo.co.in, sibandap@ukzn.ac.za Orcid id: https://orcid.org/0000-0002-9348-4651, https://orcid.org/0000-0002-9153-300X, https://orcid.org/0000-0003-2115-4642 Manuscript Received: 02 November 2017, Accepted 04 February 2018
} 
Recent studies attempt at overcoming the over simplified approach of prior studies to nonlinear thermal radiation by considering it as the fourth power of the temperature and the nonlinearity was not resolved using Taylor series. The current study employs the same approach to nonlinear thermal radiation as $[9,10]$.

Many chemically reacting systems involve both homogeneous and heterogeneous reactions, with examples occurring in combustion, catalysis and biochemical processes. The interaction between the homogeneous reactions in the bulk of the fluid and heterogeneous reactions occurring on some catalytic surfaces is generally very complex and is involved in the production and consumption of reactant pieces at different rates both within the fluid and the catalytic surfaces. The first study on homogeneous and heterogeneous reactions in boundary layer flow was addressed by Chaudhary et al [11]. They presented a simple model of homogeneous-heterogeneous reactions for forced convection near leading edge of the plate. Merkin[12] used the same model to considered the problem of a homogeneous reaction defined by cubic auto-catalysis and the heterogeneous reaction by a first order process in the boundary layer flow of a viscous fluid past a flat plate. A numerical study of the Homogeneous-heterogeneous reactions in micropolar fluid flow from a permeable stretching or shrinking sheet in a porous medium was conducted by Shaw et al. [13]. The study shown that the solutions are possible for all positive values of the stretching parameter, while solutions are possible only for a limited range of values for shrinking surface. Goyal et al. [14] studied the boundary layer flow and heat transfer of viscoelastic nanofluids past a stretching sheet with partial slip condition. A homogeneous-heterogeneous reaction on boundary layer flow of fluid at a stagnation point over a porous stretching sheet take into account the partial slip condition was discussed by Mariam et al. [15]. Bachok et al. [16] examined the homogeneous-heterogeneous reactions boundary layer flow close to the stagnation point past a stretching surface. The analytic solution of the homogeneous-heterogeneous reactions on Powell-Eyring fluid flow through a stretching sheet was addressed by Hayat et al. [17]. Entropy quantifies the molecular disorder (randomness) of systems. The second law of thermodynamics indicates that the entropy generation is positively correlated with the irreversible processes; that is, entropy generation $\left(N_{G}\right)$ is always positive during irreversible processes. On contrary, the entropy of a system stays unchanged during reversible processes. Since the performance of engineering systems deteriorate by irreversible process, it follows that the entropy generation affects the performance of such systems negatively. Therefore, the entropy generation is sometimes regarded as a measure of the magnitude of the irreversibility of a process. Little attention has been paid to the study of entropy generation and the impact of the Bejan number $(B e)$ on the viscoelastic nanofluid. This study the mechanisms for generating entropy are related to heat transfer, magnetic field, fluid friction irreversibility and mass transfer. Mirzazadeh et al. [18] studied the concept of entropy generation and the impact of the Bejan number $(B e)$ on viscoelastic fluid past rotating cylinders. The application of the second law analysis to viscoelastic MHD flow through a stretching sheet was scrutinized by Soraya et al. [19]. Mishra et al. [20] analyzed the influence of thermal radiation over a stretching plate.

The motivation of the present study is to investigate the entropy generation and Bejan number for steady twodimensional MHD flow, heat and mass transfer of an incompressible viscoelastic nanofluids over a linearly stretching sheet with homogeneous-heterogeneous chemical reaction and thermal radiation. To the best of the authors knowledge no paper in the research has so far studied entropy generation and Bejan number in viscoelastic nanofluid over a stretching sheet with homogeneous-heterogeneous reaction. The present study has many applications in cooling of metallic plate, movement of biological fluids, melt spinning, heat exchangers technology, and oceanography. Precisely, both entropy generation and Bejan number are play a major role in controlling the rate of heat transfer in the proximity of the sheet. The conversations equations are solved using the spectral quasi-linearization method (SQLM). The behavior of velocity, temperature, nanoparticles volume fraction, entropy generation and Bejan number are studied and visualize graphically.

\section{MATHEMATICAL MODEL AND VALIDATION}

Consider an incompressible, steady two-dimensional and hydrodynamics laminar flow of a viscoelastic fluid flow over a linear stretching sheet subject to the magnetic field and homogeneous-heterogeneous chemical reactions. The flow field is subject to the effect of external transverse magnetic field of stretching $B_{0}$. The flow of viscoelastic fluid is restricted to region $(y>0)$ and the stagnation point is fixed at $x=0$. The wall and ambient temperature of the stretching sheet are defined as $T_{w}$ and $T_{\infty}$ respectively. $C_{a}$ and $C_{b}$ are the concentrations homogeneous and heterogeneous reactions for species $A$ and $B$ respectively. The velocity near stretching sheet denoted by $U(x)=u_{w}(x)=c x$, where $c$ represents stretching rate and $c>0$. This study considers the interaction between two different types of chemical reaction; such as, a homogeneous (bulk) and a heterogeneous (on sheet) reactions through a boundary layer flow. The reaction between species $A$ and $B$ is given by (see[11,12])

$$
\begin{aligned}
& A+B \rightarrow 3 B, \quad \text { rate }=k_{1} C_{a} C_{b}^{2}, \\
& A \rightarrow B, \quad \text { rate }=k_{s} C_{a},
\end{aligned}
$$

Using these assumptions, and the usual boundary layer approximation, the system of equations for the viscoelastic nanofluid are given by: 


$$
\begin{gathered}
\frac{\partial u}{\partial x}+\frac{\partial v}{\partial y}=0 \\
u \frac{\partial u}{\partial x}+v \frac{\partial u}{\partial y}=v \frac{\partial^{2} u}{\partial y^{2}}-\frac{k_{0}}{\rho}\left[u \frac{\partial^{3} u}{\partial x \partial y^{2}}+v \frac{\partial^{3} u}{\partial y^{3}}+\frac{\partial u}{\partial x} \frac{\partial^{2} u}{\partial y^{2}}-\frac{\partial u}{\partial y} \frac{\partial^{2} u}{\partial x \partial y}\right]-\frac{\sigma B_{0}^{2}}{\rho} u \\
u \frac{\partial T}{\partial x}+v \frac{\partial T}{\partial y}=\alpha_{m} \nabla^{2} T+\tau\left[D_{B} \frac{\partial C_{b}}{\partial y} \frac{\partial T}{\partial y}+\frac{D_{T}}{T_{\infty}}\left(\frac{\partial T}{\partial y}\right)^{2}\right]-\frac{1}{\rho C_{p}} \frac{\partial q_{r}}{\partial y} \\
u \frac{\partial C_{a}}{\partial x}+v \frac{\partial C_{a}}{\partial y}=D_{A} \frac{\partial^{2} C_{a}}{\partial y^{2}}-k_{1} C_{a} C_{b}^{2} \\
u \frac{\partial C_{b}}{\partial x}+v \frac{\partial C_{b}}{\partial y}=D_{B} \frac{\partial^{2} C_{b}}{\partial y^{2}}+\frac{D_{T}}{T_{\infty}} \frac{\partial^{2} T}{\partial y^{2}}+k_{1} C_{a} C_{b}^{2}
\end{gathered}
$$

where $\alpha_{m}=k_{f} /\left(\rho c_{p}\right)_{f}$ and $\tau=\left(\rho c_{p}\right)_{s} /\left(\rho c_{p}\right)_{f}$. Suppose $\theta_{w}=T_{w} / T_{\infty}$. Then the temperature and the nonlinear thermal relation ( $q_{r}$ is relative to heat flux ) can be written as:

$$
\begin{aligned}
& T=T_{\infty}\left[1+\left(\theta_{w}-1\right) \theta\right] \\
& \mathrm{q}_{\mathrm{r}}=-\frac{4 \sigma^{*}}{3 \mathrm{k}^{*}} \frac{\partial \mathrm{T}^{4}}{\partial \mathrm{y}}=-\frac{16 \sigma^{*}}{3 \mathrm{k}^{*}} \mathrm{~T}^{3} \frac{\partial \mathrm{T}}{\partial \mathrm{y}}
\end{aligned}
$$

The boundary conditions are

$$
\begin{aligned}
& u=U+k_{1}^{*} v \frac{\partial u}{\partial y}, v=0, T=T_{w}, D_{A} \frac{\partial C_{a}}{\partial y}=k_{s} C_{a}, D_{B}=\frac{\partial C_{b}}{\partial y}=-k_{s} C_{a} \text { at } y=0, \\
& u=0, T=T_{\infty}, C_{a} \rightarrow C_{\infty}, C_{b} \rightarrow 0 \text { at } y \rightarrow \infty .
\end{aligned}
$$

To simplify the equations, we introduce the following similarity transformations:

$$
\begin{aligned}
& \eta=\sqrt{\frac{c}{v}} y, u=c x f^{\prime}(\eta), v=-\sqrt{c v} f(\eta), \\
& \theta(\eta)=\frac{T-T_{\infty}}{T_{w}-T_{\infty}}, \xi=\frac{C_{a}}{C_{\infty}}, \phi(\eta)=\frac{C_{b}}{C_{\infty}} .
\end{aligned}
$$

The system of equations (3) -(7) is transformed to:

$$
\begin{gathered}
f^{\prime \prime \prime}+f f^{\prime \prime}-f^{\prime 2}+\alpha\left(f^{\prime \prime 2}-2 f^{\prime} f^{\prime \prime \prime}+f f^{\prime \prime \prime \prime}\right)-H a^{2} f^{\prime}=0, \\
{\left[1+N r\left\{1+\left(\theta_{w}-1\right) \theta\right\}^{3}\right\rfloor \theta^{\prime \prime}+3 N r\left(\theta_{w}-1\right)\left\{1+\left(\theta_{w}-1\right) \theta\right\}^{2} \theta^{\prime 2}+\operatorname{Pr} f \theta^{\prime}+\operatorname{Pr}\left(N b \theta^{\prime} \phi^{\prime}+N t \theta^{\prime 2}\right)=0} \\
\xi^{\prime \prime}+S c f \xi^{\prime}-K S c \xi \phi^{2}=0,
\end{gathered}
$$




$$
\frac{1}{\varepsilon S c}\left(\phi^{\prime \prime}+\frac{N t}{N b} \theta^{\prime \prime}\right)+f \phi^{\prime}+K \xi \phi^{2}=0
$$

subject to the boundary conditions:

$$
\begin{aligned}
& f(0)=0, f^{\prime}(0)=1+\lambda f^{\prime \prime}(0), \theta(0)=1, \xi^{\prime}(0)=K_{s} \xi(0), \phi^{\prime}(0)=-\varepsilon K_{s} \xi(0), \\
& f^{\prime}(\infty)=0, \theta(\infty)=0, \xi(\infty)=1, \phi(\infty)=0,
\end{aligned}
$$

where a prime refers to differentiation respect to $\eta, \lambda=k_{1}^{*} v \sqrt{c / v}, K_{S}=k_{S} / D_{A} \sqrt{c / v}, \varepsilon=D_{A} / D_{B}$. The non-dimensional parameters appearing in Equations (11)-(14) are defined as

$$
\begin{gathered}
\alpha=C k_{0} / v, H a^{2}=\sigma B_{0}^{2} / \rho c, \operatorname{Pr}=\mu c_{p} / k_{f}, N r=16 \sigma^{*} T_{\infty}^{3} / 3 k^{*} k_{f}, N b=\tau D_{B} C_{\infty} / v \\
N t=\tau D_{T}\left(T_{w}-T_{\infty}\right) / v T_{\infty}, S c=v / D_{B}
\end{gathered}
$$

Although in many practical scenarios the sizes of the diffusion coefficient of the chemical species of $A$ and $B$ are not equal, they could be of a comparable size. Thus, it is not unrealistic to assume that $D A=D B$ (consequently, $\varepsilon=1)$, [21]. This assumption leads to

$$
\xi(\eta)+\phi(\eta)=1
$$

Consequently, Equations (13) and (14) can be reduced to a single equation as follows

$$
\xi^{\prime \prime}-\frac{\mathrm{Nt}}{\mathrm{Nb}} \theta^{\prime \prime}+\mathrm{Scf} \xi^{\prime}-\mathrm{ScK} \xi(1-\xi)^{2}=0
$$

with the boundary conditions

$$
\xi^{\prime}(0)=\mathrm{K}_{\mathrm{s}} \xi(0), \xi(\infty)=1
$$

Hence the system in equations (11) to (14) become

$$
\begin{gathered}
\mathrm{f}^{\prime \prime \prime}+\mathrm{ff} \mathrm{f}^{\prime \prime}-\mathrm{f}^{\prime 2}+\alpha\left(\mathrm{f}^{\prime \prime 2}-2 \mathrm{f}^{\prime} \mathrm{f}^{\prime \prime \prime}+\mathrm{ff}^{\prime \prime \prime \prime}\right)-\mathrm{Ha}^{2} \mathrm{f}^{\prime}=0 \\
\left\lfloor 1+N r\left\{1+\left(\theta_{w}-1\right) \theta\right\}^{3}\right] \theta^{\prime \prime}+3 N r\left(\theta_{w}-1\right)\left\{1+\left(\theta_{w}-1\right) \theta\right\}^{2} \theta^{\prime 2}+\operatorname{Pr} f \theta^{\prime}+\operatorname{Pr}\left(N b \theta^{\prime} \phi^{\prime}+N t \theta^{\prime 2}\right)=0 \\
\xi^{\prime \prime}-\frac{\mathrm{Nt}}{\mathrm{Nb}} \theta^{\prime \prime}+\mathrm{Sc} \xi^{\prime}-\mathrm{ScK} \xi(1-\xi)^{2}=0
\end{gathered}
$$

with the new boundary conditions

$$
\begin{aligned}
& f(0)=0, f^{\prime}(0)=1+\lambda f^{\prime \prime}(0), \theta(0)=1, \xi^{\prime}(0)=K_{s} \xi(0), \\
& f^{\prime}(\infty)=0, \theta(\infty)=0, \xi(\infty)=1,
\end{aligned}
$$

The skin friction coefficient $C_{f}$, the local Nusselt number $N u_{x}$ and the Sherwood number $S h_{x}$ are the most significant physical quantities which are given by:

$$
C_{f}=\frac{\tau_{w}}{\rho u_{w}^{2}}, \quad N u_{x}=\frac{x h_{w}}{k\left(T_{w}-T_{\infty}\right)} \text { and } S h_{x}=\frac{x h_{m}}{D_{B} C_{\infty}}
$$


where $\tau_{w}, h_{w}$ and $h_{m}$ are given by:

$$
\tau_{w}=\mu\left(\frac{\partial u}{\partial y}\right)_{y=0}, h_{w}=-k\left(\frac{\partial T}{\partial y}\right)_{y=0} \text { and } h_{m}=-D_{B}\left(\frac{\partial C_{a}}{\partial y}\right)_{y=0}
$$

Using Equation (9) and Equation (25) the Equation (24) becomes as:

$$
\mathrm{C}_{\mathrm{f}} R e^{1 / 2}=\mathrm{f}^{\prime \prime}(0), \operatorname{Re}^{-1 / 2} \mathrm{Nu}_{\mathrm{x}}=-\left(1+\mathrm{Nr} \theta_{\mathrm{w}}{ }^{3}\right) \theta^{\prime}(0) \text { and } R e^{-1 / 2} \mathrm{Sh}_{\mathrm{x}}=-\xi^{\prime}(0)
$$

where $R e=\frac{U(x) x}{v}$ is the Reynolds number.

\section{Entropy Generation:}

Entropy measures the chaos of a certain system. Entropy generation depends on procedures reversibility. In isolated systems, it is usually the case where there is a rise in entropy over time for reversible reactions. In present days, the applications of nanofluids in medical and engineering settings, have increased substantially which give more credits to the studies which investigate the influence of nanoparticles on entropy generation, [22,23]. In this study the focus is on entropy generation in the viscoelastic nanofluid.

The volumetric rate of local entropy generation, which is based on the second law of thermodynamics, is given by:

$$
\mathrm{S}_{\mathrm{gen}}^{\prime \prime \prime}=\frac{\mathrm{k}_{\mathrm{f}}}{\mathrm{T}_{\infty}^{2}}\left(1+\frac{16 \sigma^{*} \mathrm{~T}^{3}}{3 \mathrm{k}^{*} \mathrm{k}_{\mathrm{f}}}\right)\left(\frac{\partial \mathrm{T}}{\partial \mathrm{y}}\right)^{2}+\frac{\sigma \mathrm{B}_{0}^{2}}{\mathrm{~T}_{\infty}} \mathrm{u}^{2}+\frac{\mathrm{R} \mathrm{D}_{\mathrm{B}}}{\mathrm{T}_{\infty}} \frac{\partial \mathrm{T}}{\partial \mathrm{y}} \frac{\partial \mathrm{C}_{\mathrm{a}}}{\partial \mathrm{y}}+\frac{\mathrm{RD}_{\mathrm{B}}}{\mathrm{C}_{\infty}}\left(\frac{\partial \mathrm{C}_{\mathrm{a}}}{\partial \mathrm{y}}\right)^{2}
$$

where in Equation (27), the first term is irreversibility caused by heat transfer, the second term is the entropy generation due to the influence of the magnetic field and the third and fourth terms are irreversibility caused by diffusion effect.

It is suitable to define the entropy generation number $N_{G}$ as a ratio between the local volumetric entropy generation rate $S_{g e n}^{\prime \prime}$ and a characteristic rate of entropy generation which is defined by $S_{0}^{\prime \prime \prime}$

$$
S_{0}^{\prime \prime \prime}=\frac{k_{f}\left(T_{w}-T_{\infty}\right)}{T_{\infty}^{2} x^{2}}
$$

By using Equations $(27-28)$ and Equation (10) the entropy generation in $\operatorname{dimensionless} N_{G}$ is given by:

$$
\mathrm{N}_{\mathrm{G}}=\operatorname{Re}\left\{1+\mathrm{Nr}(1+\chi \theta)^{3}\right\} \theta^{\prime 2}+\frac{\operatorname{Re} \mathrm{BrHa}^{2}}{\chi} \mathrm{f}^{\prime 2}+\frac{\operatorname{Re} \sum}{\chi} \theta^{\prime} \xi^{\prime}+\frac{\operatorname{Re} \sum}{\chi^{2}} \xi^{\prime 2}
$$

The numbers and parameters in Equation (29) can be obtained as:

$$
R e=\frac{\mathrm{u}_{\mathrm{w}}(\mathrm{x}) \mathrm{x}}{\mathrm{v}}, \mathrm{Br}=\frac{\mu \mathrm{u}_{\mathrm{w}}^{2}(\mathrm{x}) \mathrm{x}}{\mathrm{k}_{\mathrm{f}} \Delta \mathrm{T}}, \Delta \mathrm{T}=\mathrm{T}_{\mathrm{w}}-\mathrm{T}_{\infty}, \sum=\frac{\mathrm{C}_{\infty} \mathrm{RD}}{\mathrm{k}_{\mathrm{f}}}, \chi=\left(\Theta_{\mathrm{w}}-1\right)
$$

Equation (29) can be obtained as a summation of the entropy generation number caused by the heat transfer $\left(\mathrm{N}_{1}\right)$ and the entropy generation number caused by both diffusive irreversibility and magnetic field $\left(N_{2}\right)$. That is $N_{G}=$ $N_{1}+N_{2}$, where

$$
\begin{gathered}
N_{1}=\operatorname{Re}\left\{1+N r(1+\chi \theta)^{3}\right\} \theta^{\prime 2} \\
\mathrm{~N}_{2}=\frac{\operatorname{ReBrH\mathrm {Ba}^{2}}}{\chi} \mathrm{f}^{\prime 2}+\frac{\operatorname{Re} \sum}{\chi} \theta^{\prime} \xi^{\prime}+\frac{\operatorname{Re} \sum}{\chi^{2}} \xi^{\prime 2}
\end{gathered}
$$


The heat transfer irreversibility, diffusive irreversibility and the magnetic field all contribute to entropy generation. It is therefore worthwhile investigating the conditions under which heat transfer dominates entropy generation. To investigate this question, the Bejan $(B e)$ number is defined as the ratio of entropy generation due to heat transfer and the entropy generation number.

$$
B e=\frac{N_{1}}{N_{G}}=\frac{1}{1+\Phi}
$$

where $\Phi=N_{2} / N_{1}$ represents the irreversibility ratio. Depending on $\Phi$, different factors contribute differently on entropy generation. When $0 \leq \Phi<1$, heat transfer is the most dominant factor in entropy generation. When $\Phi>1$, the irreversibility diffusive with the magnetic effects dominate on entropy generation. When $\Phi=1$ heat transfer and diffusion with magnetic effects contributes equally on entropy generation. The Bejan number takes values in range $[0,1]$ (see $[23,24,25,26,27,28])$. At the extreme when $B e=1$ the irreversibilityof heat transfer dominates. On the other extreme when $B e=0$ the combined effects of diffusion and magnetic field dominates the irreversibility. When $B e=0.5$, the contribution of heat transfer in entropy generation is the same as the combined contribution of diffusion and magnetic field in entropy generation. Additionally, the Bejan number $B e$ is considered at the best values of the parameters at which the entropy generation its minimum.

\section{RESULTS AND DISCUSSION}

The study addresses entropy generation and the impact of the Bejan number in a steady two-dimensional MHD viscoelastic nanofluid flow that is subject to homogeneous and heterogeneous chemical reactions, the effect of the slip and the nonlinear thermal radiation. The spectral quasi-linearization method (SQLM) is used to solve the conservation equations. The SQLM is used in the literature because it gives accurate results for boundary layer type equations (see $[29,30])$

The effect of flow parameters on velocity, temperature and concentration profiles as well as the skin friction coefficient, local Nusselt number and Sherwood number is investigated and provided in tables and graphs. The variation in the skin friction coefficient with different values of the viscoelastic parameter the partial slip parameter and the Hartmann number are provided in Table 1. It is observed that the skin friction decreases with the viscoelastic parameter and the Hartmann number, in contrast, it increases with $\lambda$. Numerical values of the local Nusselt number and Sherwood number with variations in the homogeneous reaction parameter, the heterogeneous reaction parameter, the nonlinear thermal radiation parameter, the temperature ratio parameter and the Thermophoresis parameter are tabulated in Table 2. It is noted that the Nusselt number increases with the heterogeneous reaction parameter, the nonlinear thermal radiation parameter, the temperature ratio parameter and the Thermophoresis parameter whereas homogeneous reaction parameter reduces the Nusselt number. In addition, in Table 2, it is observed that the homogeneous reaction parameter enhances the value of Sherwood number which is decreasing with heterogeneous reaction parameter, the nonlinear thermal radiation parameter, the temperature ratio parameter and the Thermophoresis parameter.

Table 1. Numerical values of $f^{\prime \prime}(0)$ with various values of $\alpha, \lambda$ and $H a$ when $N b=0.5, S c=2, \operatorname{Pr}=6.8, K=0.5$, $K_{s}=1, N r=0.5, N t=0.2, \theta_{w}=10.1$.

\begin{tabular}{|c|c|c|c|}
\hline$\alpha$ & $\lambda$ & $H a$ & $C_{f} R e^{1 / 2}$ \\
\hline 0.5 & 0.3 & 0.5 & -0.90425116 \\
0.7 & & & -0.97468978 \\
0.9 & 0.1 & 0.5 & -1.06029277 \\
\hline 0.2 & 0.5 & & -1.05590404 \\
& 0.7 & 0.2 & -0.57757067315 \\
\hline 0.2 & 0.3 & 0.7 & -0.75761100 \\
& & 1 & -0.88164753 \\
& & & -0.98974875 \\
\hline
\end{tabular}


Table 2. Numerical values of $-\theta^{\prime}(0)$ and $-\xi^{\prime}(0)$ with different values of $K, K_{s} N r$, and $N t$.

\begin{tabular}{|c|c|c|c|c|c|c|}
\hline$K$ & $K_{s}$ & $N r$ & $\theta_{w}$ & $N t$ & $R e^{-1 / 2} N u_{x}$ & $R e^{-1 / 2} S h_{x}$ \\
\hline 0.1 & 1 & 0.5 & 1.01 & 0.2 & -0.44290300 & -0.29765451 \\
0.3 & & & & & -0.45256076 & -0.24036655 \\
0.7 & & & & & -0.50454819 & -0.09720213 \\
\hline 0.5 & 0.5 & 0.5 & 1.01 & 0.2 & -0.49842157 & -0.11927642 \\
& 3 & & & & -0.43654921 & -0.24314929 \\
& 7 & & & & -0.42046705 & -0.28069503 \\
\hline 0.5 & 1 & 1 & 1.01 & 0.2 & -0.39239089 & -0.08202508 \\
& & 1.5 & & & -0.36069650 & -0.08361434 \\
& & 2 & & & -0.33377872 & -0.08566399 \\
\hline 0.5 & 1 & 0.5 & 1.5 & 0.2 & -0.33609133 & -0.13436426 \\
& & & 2 & & -0.23905902 & -0.14421738 \\
& & & 2.5 & & -0.17085877 & -0.14991236 \\
\hline 0.5 & 1 & 0.5 & 1.01 & 1.5 & -0.18792574 & -0.15174783 \\
& & & & 2 & -0.14148245 & -0.17675215 \\
& & & & 2.5 & -0.11188459 & -0.19531184 \\
\hline
\end{tabular}

The variability on the velocity, temperature and concentration profiles with various values of the partial slip parameter is displayed in Figure 2. It is noted that the influence of increasing partial slip parameter shifts streamline to boundary layer such that the momentum boundary layer becomes thicker. Therefore, partial slip parameter decreases the boundary layer velocity and concentration while the temperature increases with partial slip parameter.

Figure 3 shows the effect of different values of the Hartmann number on the velocity, temperature and concentration profiles. It is observed that an increase in the Hartmann number leads to reduction in both velocity and concentration profiles whereas it leads to an increase in temperature profile. The depreciation in velocity profile can be attributed to the presence of Lorentz force which prevails over the boundary layer when Hartmann number increases and thus leads to an increase in the viscous force which, in turn, resists velocity profile.

The effects of various values of the Brownian motion parameter on the temperature and concentration profiles is presented in Figure 4. It is deduced that Brownian motion parameter is proportionally related to temperature and concentration profiles. However, the large values of Brownian motion parameter lead to an enhancement of the concentration. Further, the variation in Brownian motion parameter produces homogeneous and heterogeneous mixing which promotes the thermal conductivity of the viscoelastic nanofluid. Thus, the higher thermal conductivity causes to increase both the temperature and the chemical specie concentration.

The variation in the temperature profile according to the varying values of the nonlinear thermal radiation parameter is demonstrated in Figure 5. It is noted that the temperature increases with increased nonlinear thermal radiation parameter, which is consistent with physical observations regarding to the effect of increasing thermal radiation.

Figure 6 shows the effect of the Thermophoresis parameter on the temperature profile. It is noted that as temperature profile increases, Thermophoresis parameter also increases. From Equation (12), Thermophoresis parameter isproportionally related to the temperature profile.

The behavior of the concentration profile with increasing values of the stretching homogeneous parameter and the stretching heterogeneous parameter is depicted in Figure 7 and Figure 8. Further, from the figures, it is observed theboundary conditions at the wall $(y=0)$ and far away from the sheet (streamline $y=\infty)$ are satisfied. The concentration profile increases negligibly with homogeneous parameter and heterogeneous parameter. This effect occurs only in the vicinity of the wall.

Figure 9 represents the influence of Prandtl number on the temperature and concentration profiles. It is noted that an increases in $P r$ tends to decreases in temperature profile and increases in concentration profile. The deterioration in the concentration profile as a result of increasing values of Prandtl can be linked to the thinner thermal boundary layer (low temperature) caused by reduction of thermal diffusion of the fluid layers which is directly related to increase in Prandtl number.

The changing in the temperature and concentration profiles with an increase in the temperature ratio parameter is exhibited in Figure 10. An increase of temperature ratio parameter results in the increase of temperature and concentration profiles, at the proximity of the sheet. However, in ranges not very far from the sheet $(\eta=3.5)$, concentrationprofile decreases with increasing temperature ratio parameter. 


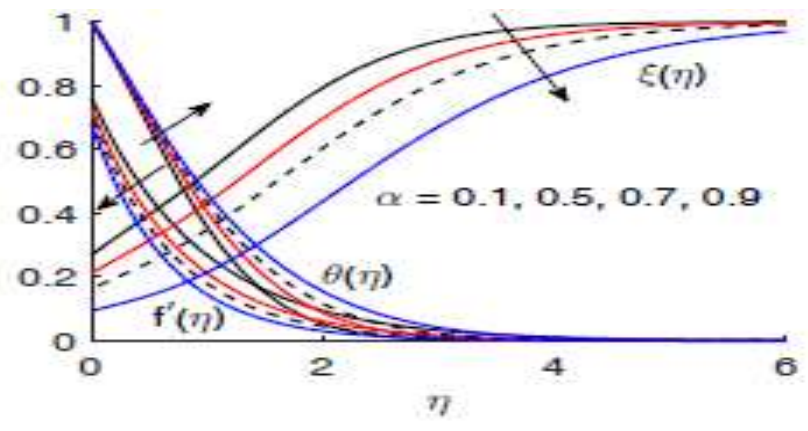

Figure 1. Effects of viscoelastic parameter $(\alpha)$ on the velocity, temperature and concentration profiles

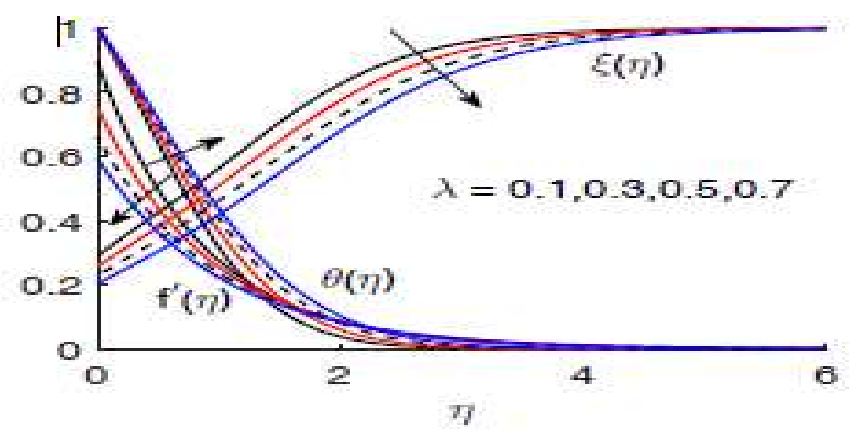

Figure 2. Effects of velocity, temperature and concentration parameter for different values of velocity slip $\operatorname{parameter}(\lambda)$

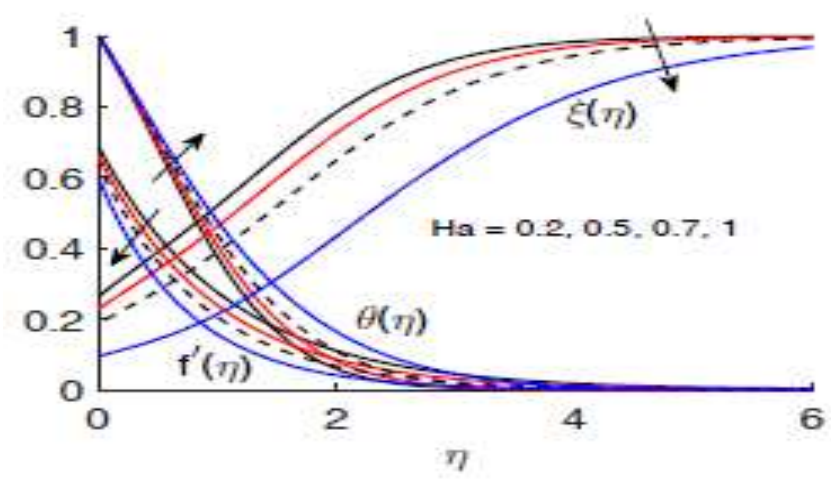

Figure 3. Effects of the Hartmann number $(\mathrm{Ha})$ on the velocity, temperature and concentration profiles

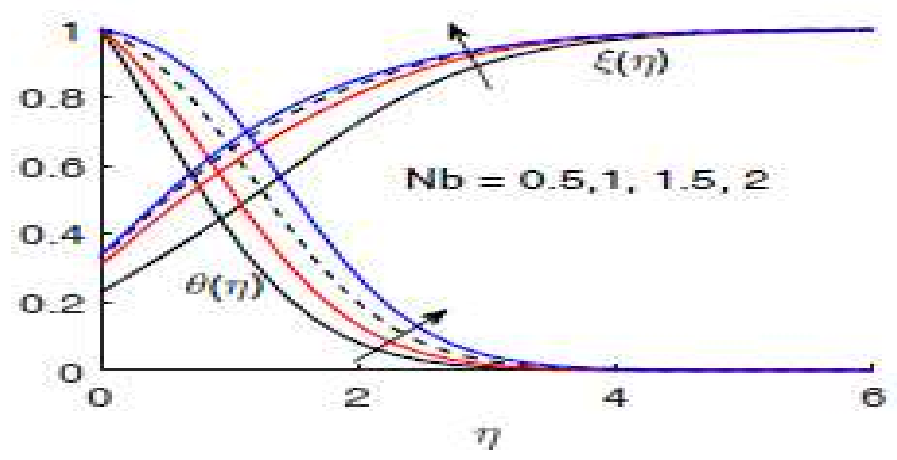

Figure 4. Effects of temperature and concentration parameter for different values of $(\mathrm{Nb})$ 


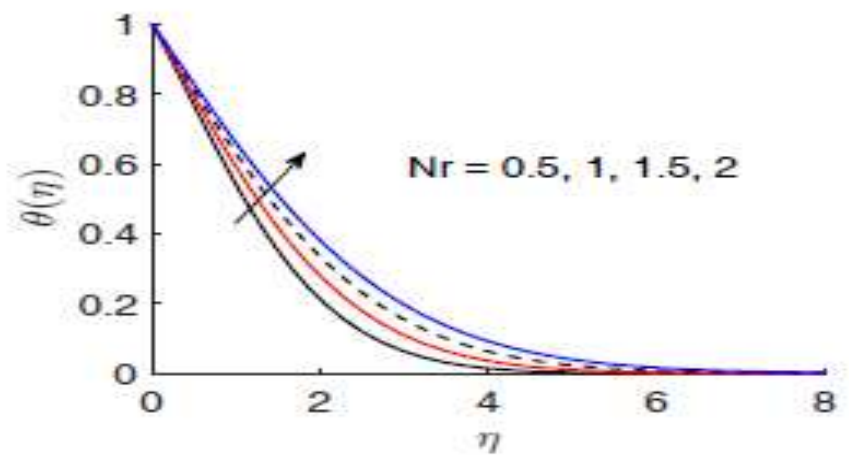

Figure 5. Effects of the thermal radiation parameter $(\mathrm{Nr})$ on the temperature profile

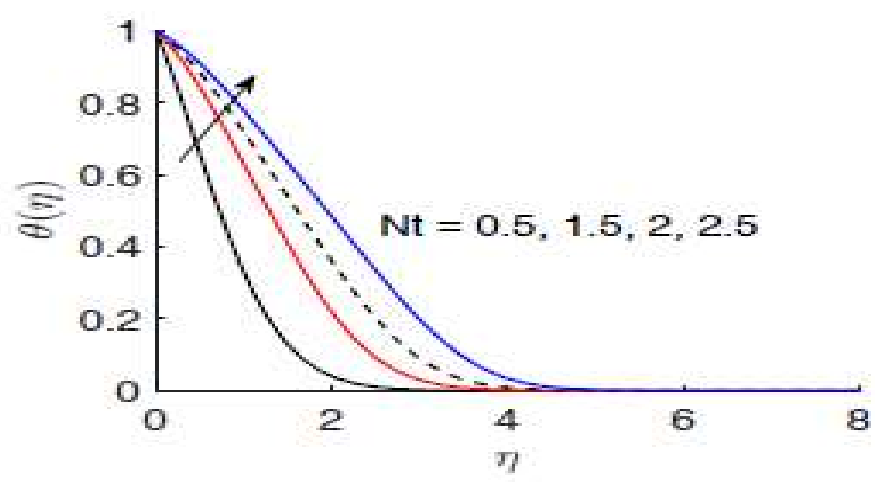

Figure 6. Effects of the Thermophoresis parameter $(N t)$ on the temperature profile

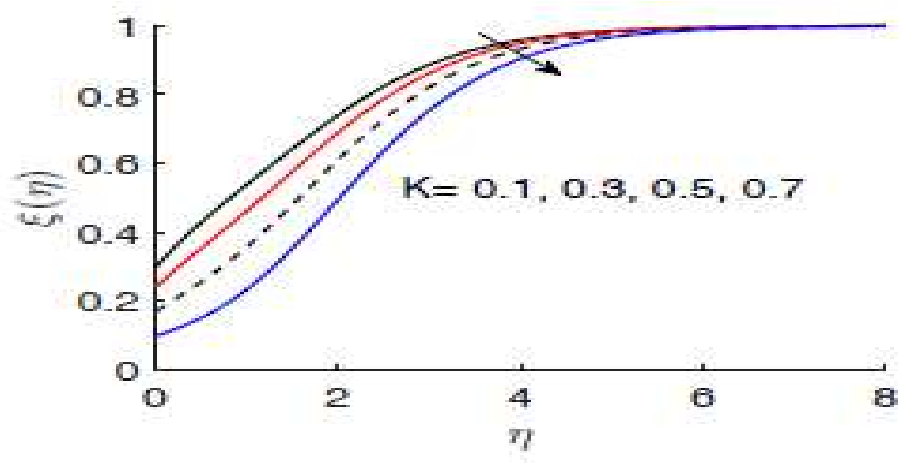

Figure 7. Effects of concentration profile for different values of homogeneous parameter $(K)$

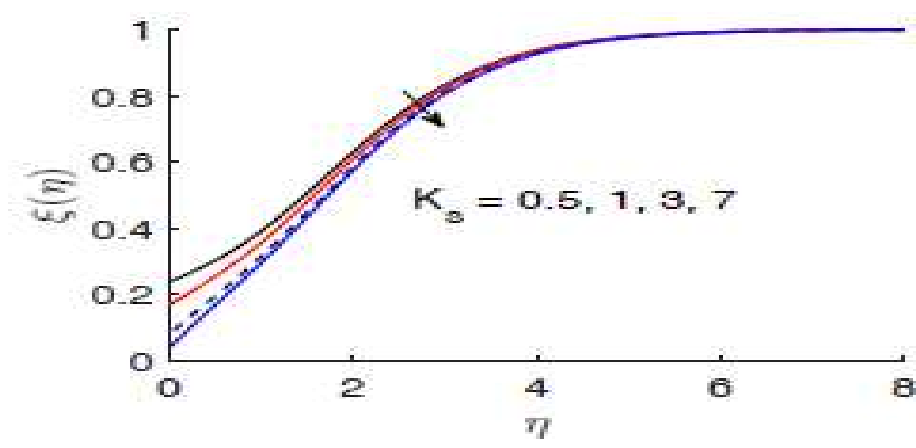

Figure 8. Effects of concentration profile for different values of heterogeneous parameter $\left(K_{s}\right)$ 


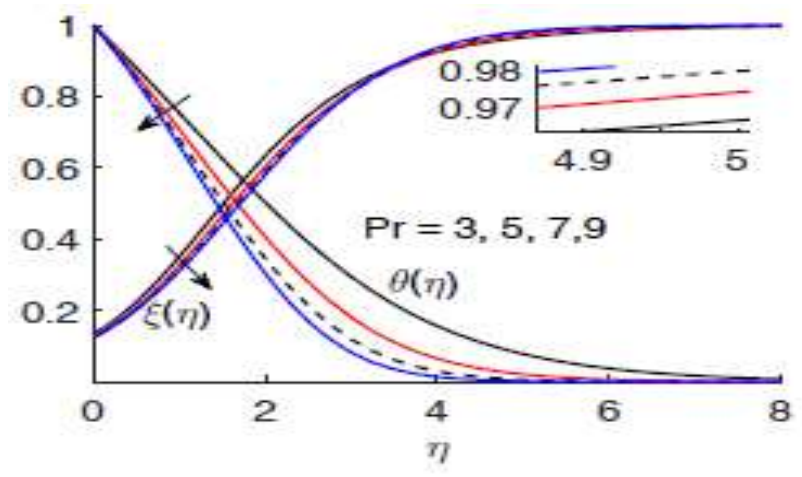

Figure 9. Effects of the Prandtl number $(\mathrm{Pr})$ on the temperature and concentration profiles

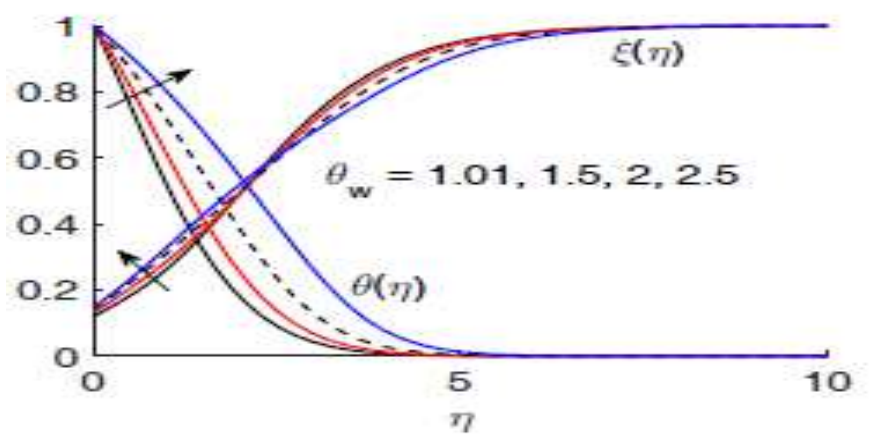

Figure 10. Effects of the temperature ratio parameter $\left(\theta_{w}\right)$ on the temperature and concentration profiles

The behavior of dimensionless entropy generation profile represents one of the most important characteristics of this study. The variation in entropy generation profile is examined and exhibited in different figures with different values of the pertinent parameters, namely, the Hartmann number, the Brinkman number, the dimensionless parameter, the viscoelastic parameter, the Reynolds number and the partial slip parameter respectively. It is worth noting that Figures (11) - (17) provide several ways to control the entropy generation number.

Figure 11 shows the effect of the Hartmann number on the entropy generation number. An increase in Hartmannnumber results in the increment of the entropy generation number. In the neighborhood of the sheet vicinity, Hartmann number has significant impact on the entropy generation number, whereas at regions far away from the sheet, the Hartmann number has slight effect on the entropy generation number. This effect tends to increase the resistance of the fluid motion, consequently the heat transfer rates increase, which result in an increase in the entropy generation number. However, at far from the sheet vicinity, the influence of Hartmann number is insignificant.

Figure 12 displays entropy generation with the Brinkman number, which represents a measure of the significance of the heat produced by viscous heating proportional to heat transported by molecular conduction. An increase in the Brinkman number tends to increase the entropy generation number especially in the vicinity of the sheet. Heat generated by viscous dissipation prevails through the heat transported via the molecular conduction in the neighborhood of the sheet. In the vicinity of the sheet, essential heat generation occurs over the boundary layer of the moving fluid particles, which trends the entropy generation number to enhance by increasing the degree of disorder of the system.

The variation in the entropy generation number with different values of the Prandtl number is illustrated in Figure 13. It is noted that an increase in the Prandtl number leads to an increase in the entropy generation number in the neighborhood to the sheet. However, in ranges not very far from the sheet, entropy generation number decreases with increasing the value of the Prandtl number. Furthermore, in the proximity of the sheet, the entropy generation number increases with a rise in the Prandtl number because the concentration profile shows a substantial decrease as Prandtl number increases (see Figure 9). Further, for a fixed value of Prandtl number, entropy generation number decreases gradually as moving away from the sheet until it extinguishes completely.

Figure 14 shows the behavior of the entropy generation number with the temperature ratio parameter. It can be observed that in the neighborhood of the sheet, the entropy generation number decreases with increasing the temperature ratio parameter. However, in ranges not very far from the sheet, an increase in the temperature ratio parameter tends to an increase in the entropy generation number. Moreover, in the proximity of the sheet, the entropy generation number decreases with a rise in the temperature ratio parameter because the concentration profile illustrates a great increase with 
increasing the temperature ratio parameter (see Figure 10). Further, for a fixed value of the temperature ratio parameter, the entropy generation number increases gradually as moving away from the sheet.

Figure 15 shows the influence of the viscoelastic parameter on the entropy generation number. It is worth noting that the entropy generation number is proportionally related to the viscoelastic parameter especially in the vicinity of the sheet. Figure 16 relates the entropy generation number with the Reynolds number. It is noted that the Reynolds number has remarkable effects on the entropy generation number as an increase in the Reynolds number leads to a significant increase in the entropy generation number, in the vicinity of the sheet. As Reynolds number increases, the entropy generation number caused by the heat transfer dominates the entropy generation number caused by the diffusion effect and the magnetic field in the neighborhood of the stretching sheet. This effect makes the fluid motion more random to the extent that troubled fluid motions arise. Consequently, the entropy generation number increases due to the contribution of heat transfer. Moreover, when Reynolds number increases, the inertia forces are promoted, hence, the values of the viscous forces are decreased. By increasing the value of the Reynolds number, the acceleration of the fluid increases in the vicinity of the sheet. However, far away from the sheet these effects are negligible.

The variation in the entropy generation number with various values of the partial slip parameter is illustrated in Figure 17. It is noted that the entropy generation number decreases when partial slip parameter increase, in the vicinity of the sheet. However, when the distance becomes larger, this effect is negligible.

The entropy generation number can be due to (the diffusion effect and magnetic field) and heat transfer. Therefore, it is legitimate to investigate which of these three factors dominates the entropy generation number. To identity whether the entropy generation due to heat transfer dominates over the entropy generation due to (diffusive irreversibility and magnetic field) (and vice versa), the Bejan number is studied for different physical parameters. Moreover, the Bejan number can be used to identify the dominant irreversibility: either the heat irreversibility or the diffusion and the magnetic field irreversibility.

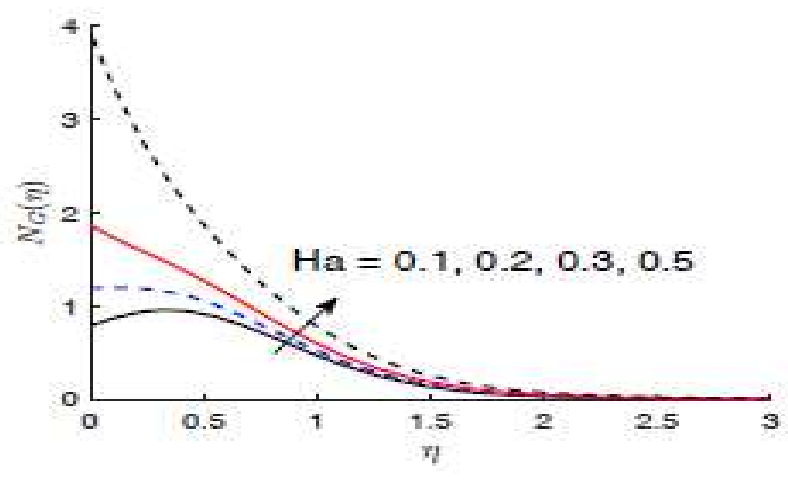

Figure 11. Effect of Hartmann number $\left(\mathrm{Ha}^{2}\right)$ on the entropy generation number $\mathrm{N}_{G}(\eta)$

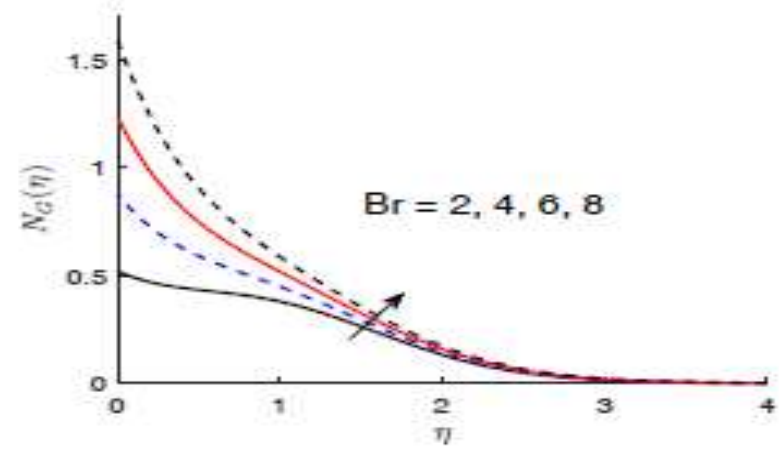

Figure 12. Effect of Brinkman number $(B r)$ on the entropy generation number $\mathrm{N}_{G}(\eta)$ 


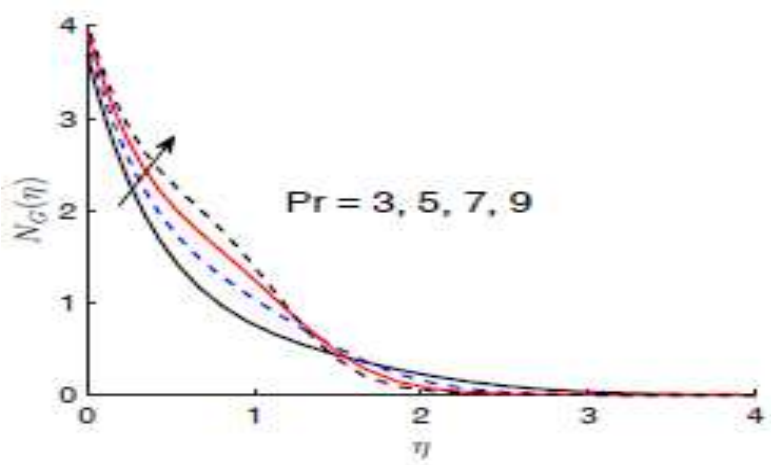

Figure 13. Effects of the Prandtl number (Pr ) on the entropy generation number $\mathrm{N}_{G}(\eta)$

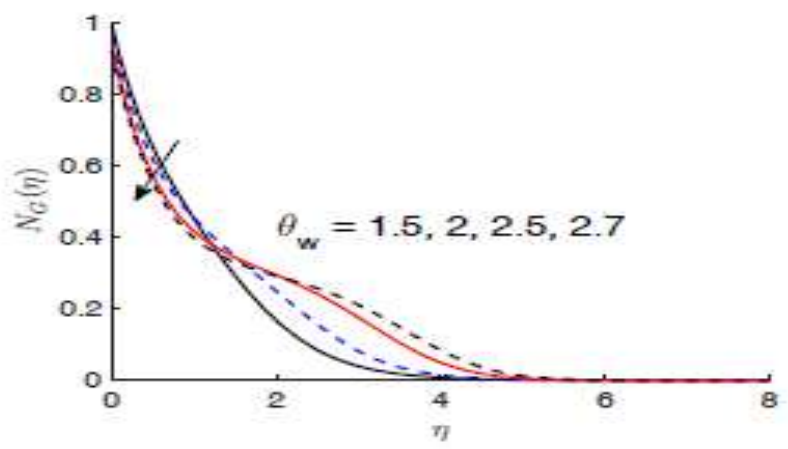

Figure 14. Effects of the temperature ratio parameter $\left(\theta_{w}\right)$ on the entropy generation number $\mathrm{N}_{G}(\eta)$

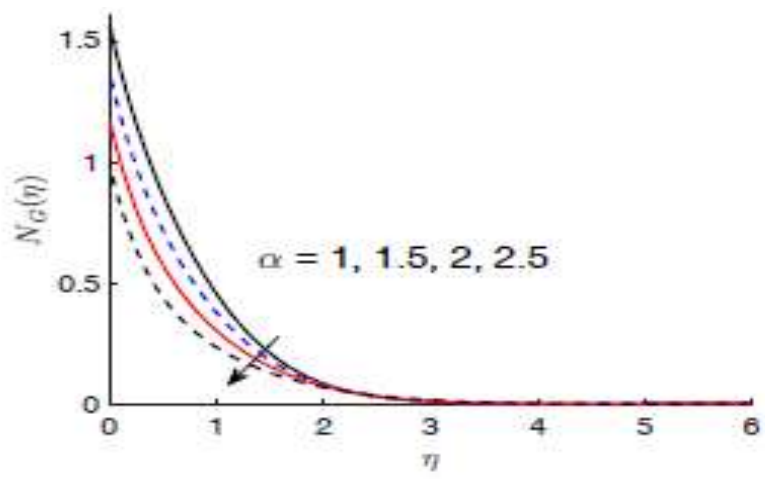

Figure 15. Effects of the viscoelastic parameter $(\alpha)$ on the entropy generation number $\mathrm{N}_{G}(\eta)$

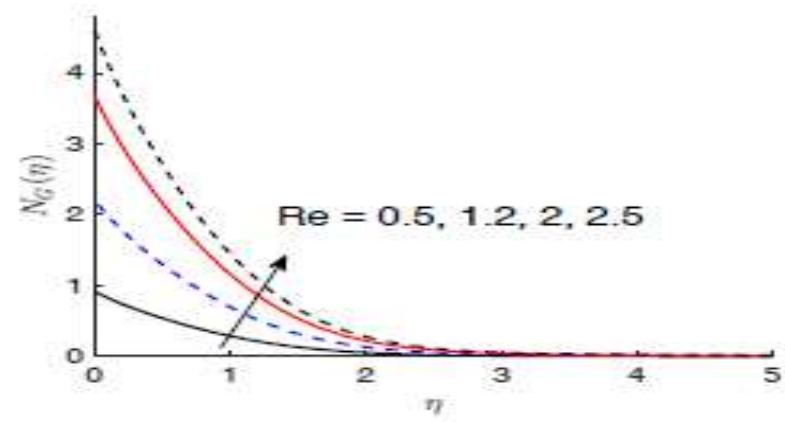

Figure 16. Effects of the Reynolds number $(R e)$ on the entropy generation number $\mathrm{N}_{G}(\eta)$ 


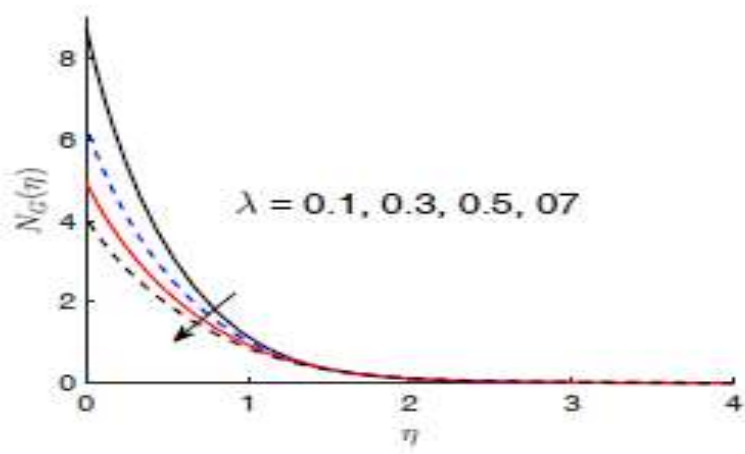

Figure 17. Effects of the partial slip parameter $(\lambda)$ on the entropy generation number $\mathrm{N}_{G}(\eta)$

Figure 18 illustrates that the Bejan number is proportionally related to the Hartmann number. As Hartmann number increases, the entropy generation traced to diffusive irreversibility and magnetic field is totally controlled by the entropy generation due to heat transfer at the vicinity of the sheet.

The variation in the Bejan number according to the viscoelastic parameter, the partial slip parameter and the dimensionless parameter respectively, are illustrated in Figures (19)- (21). It is noted that the value Bejan number increases in the neighborhood of the sheet, and it decreases gradually when the distance increases from the surface of the sheet, when viscoelastic parameter, partial slip parameter and dimensionless parameter related to the temperature ratio increasing. However, in ranges not far from the sheet, the entropy generation caused by the heat transfer is dominated as viscoelastic parameter, partial slip parameter and dimensionless parameter are enhanced.

Figure 22 and Figure 23 show the variations in the Bejan number with different values of the Brinkman number and the dimensionless parameter. It is observed that an increase in the Brinkman number and the dimensionless parameter leads to an increase in the Bejan number. From equation (31), it is noted that an increase in the Brinkman number and dimensionless parameter contribute to the increase in the magnitude of the diffusive irreversibility with the magnetic field irreversibility. However, Brinkman number and dimensionless parameter have no influence on heat transfer irreversibility, consequently, the irreversibility ratio increases and Bejan number decreases.

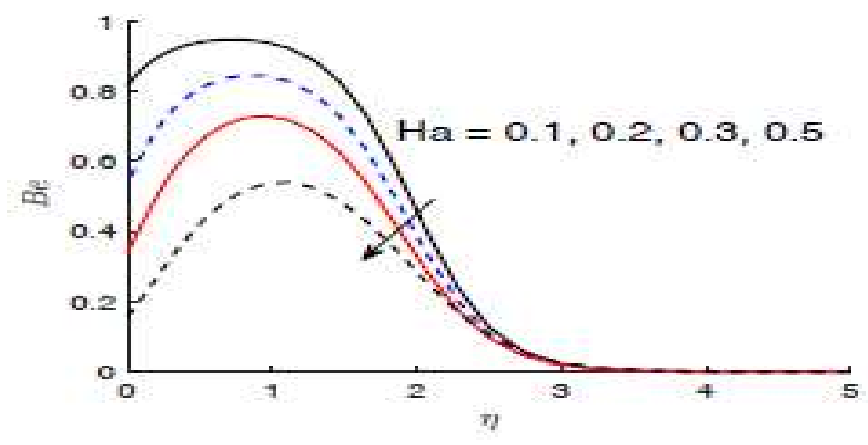

Figure 18: Effect of Hartmann number $\left(\mathrm{H}^{2}\right)$ on the Bejan number(Be)

The behavior of the skin friction coefficient, the Nusselt number and the Sherwood number with variations in the pertinent parameters is expressed in Figures (24)- (30). Figures (24)- (26) show how the skin friction, the Nusselt number and Sherwood number vary according to different values of the viscoelastic parameter and the partial slip parameter, respectively. In Figure 24 and Figure 26, it is observed that both skin friction and Sherwood number are proportionally related to the viscoelastic parameter. It is also noted that skin friction decreases with an increasing the partial slip parameter, while Sherwood number increases as partial slip parameter increases. Figure 25 shows that an increase in the viscoelastic parameter and the partial slip parameter leads to a decrease in the Nusselt number.

Figure 27 and Figure 28 demonstrate the change in the Nusselt number and Sherwood number due to the effect of the homogeneous reaction parameter and the heterogeneous reaction parameter, respectively. It is observed that the Nusselt number and the Sherwood number are a decreasing function on the heterogeneous reaction parameter. It also noted that the Nusselt number and the Sherwood number increase with an increasing the homogeneous reaction parameter. The behavior of the Nusselt number and the Sherwood number with different values of the temperature ratio parameter and the Thermophoresis parameter are displayed in Figure 29 and Figure 30 respectively. In Figure 29, it is noticed that the Nusselt number is a decreasing function on the temperature ratio parameter, moreover, it is decrease slightly as the Thermophoresis parameter increases. Figure 30 shows the effect of the temperature ratio parameter and 
the Thermophoresis parameter on the Sherwood number. These results show that the Sherwood number decreases with an increasing temperature ration parameter, whereas it is increase as the Thermophoresis parameter increases.

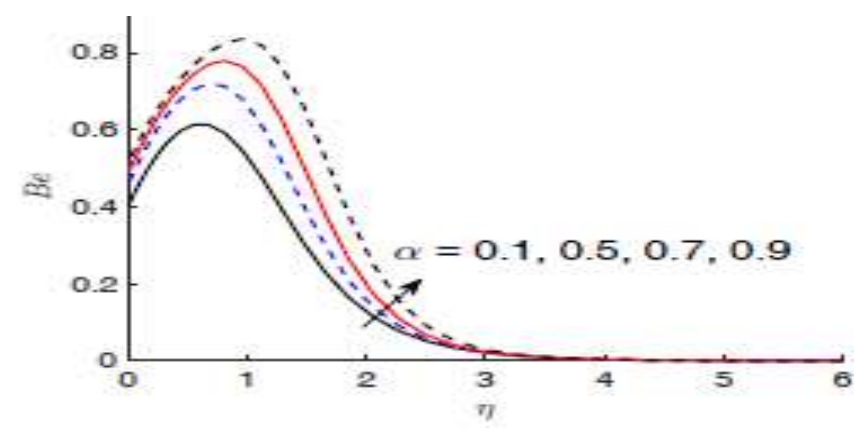

Figure 19. Effects of the viscoelastic parameter $(\alpha)$ on the Bejan number(Be)

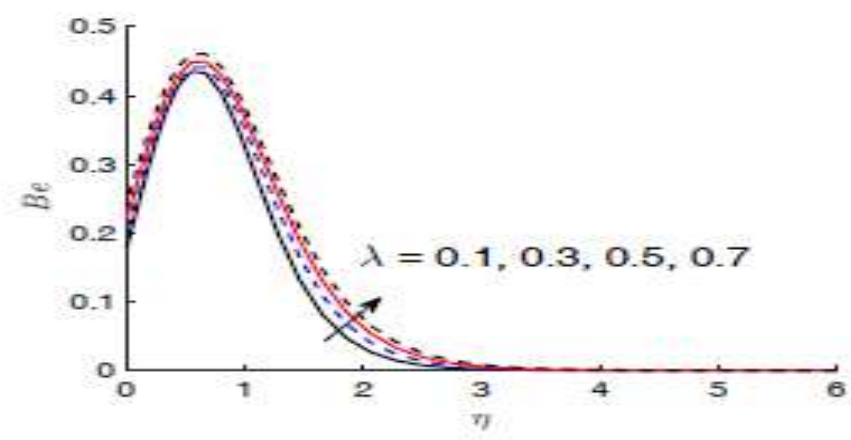

Figure 20. Effects of the partial slip parameter $(\lambda)$ on the Bejan number(Be)

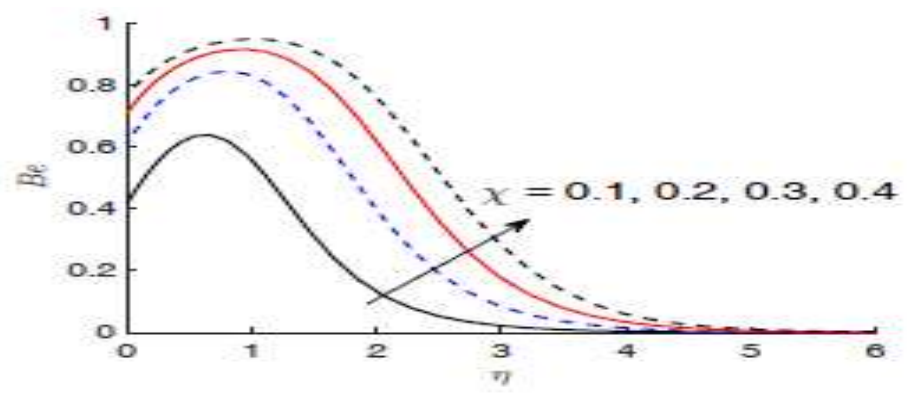

Figure 21. Effects of the dimensionless parameter $(\chi)$ on the Bejan number(Be)

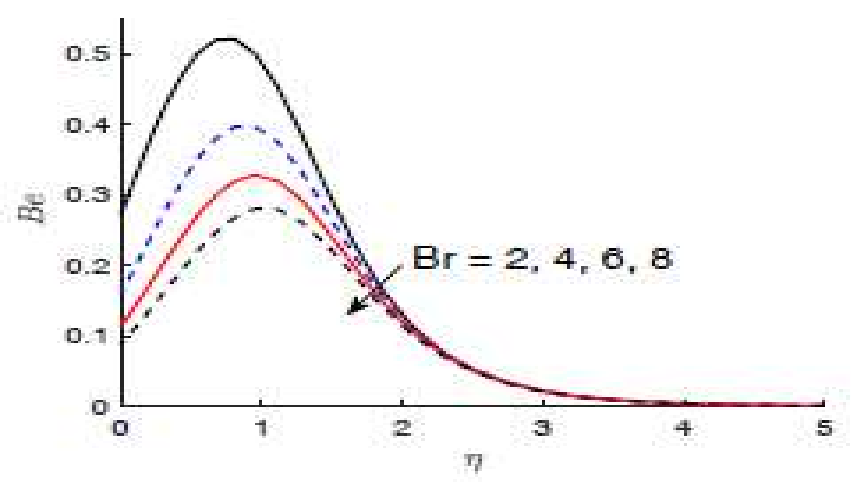

Figure 22. Effect of Brinkman number $(\mathrm{B} r)$ on the Bejan number(Be) 


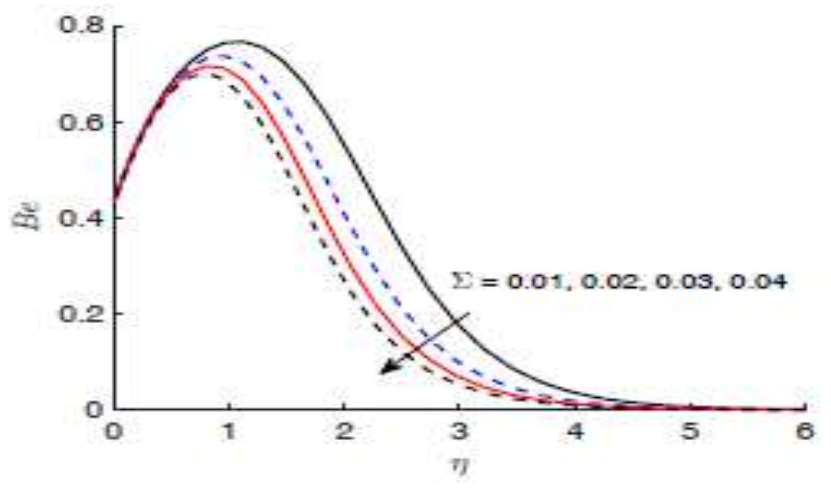

Figure 23. Effects of the dimensionless parameter $(\Sigma)$ on the Bejan $(\mathrm{B} e)$

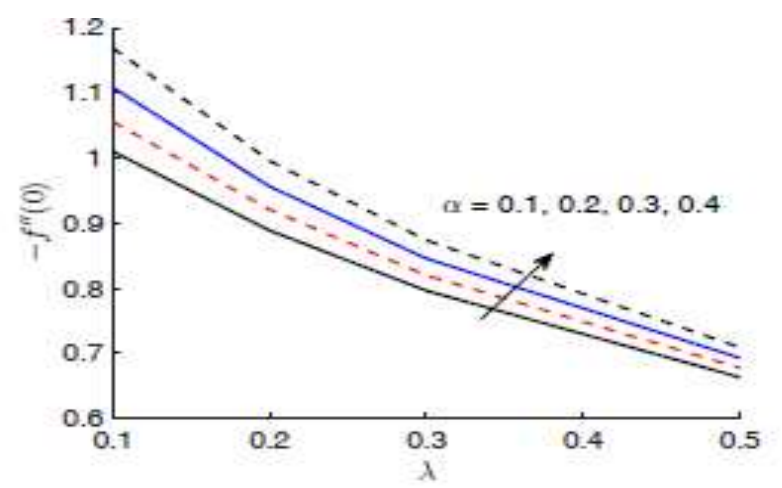

Figure 24. Effect of the viscoelastic parameter $(\alpha)$ and the partial slip parameter $(\lambda)$ on the skin friction

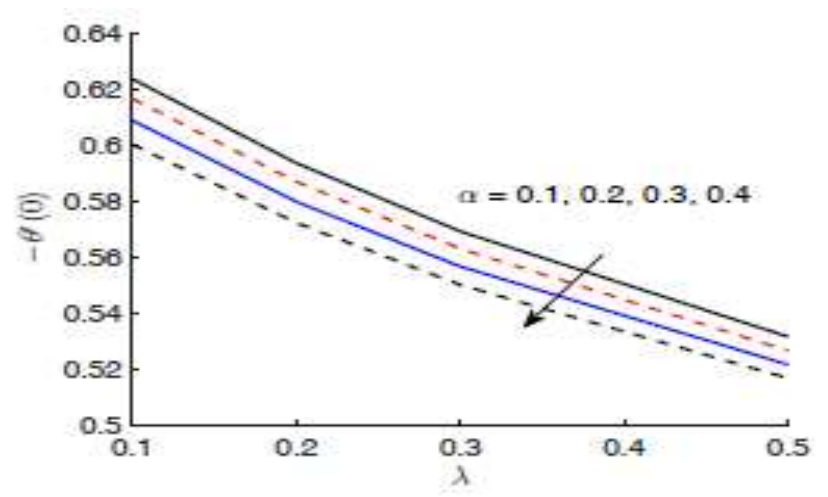

Figure 25. Effect of the viscoelastic parameter $(\alpha)$ and the partial slip parameter $(\lambda)$ on the Nusselt number

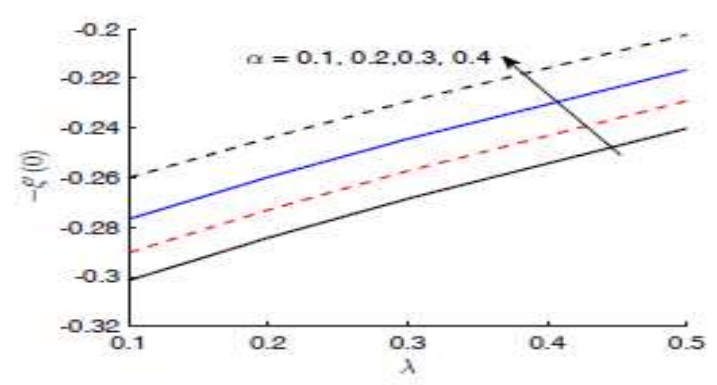

Figure 26. Effect of the viscoelastic parameter $(\alpha)$ and the partial slip parameter $(\lambda)$ on the Sherwood number 


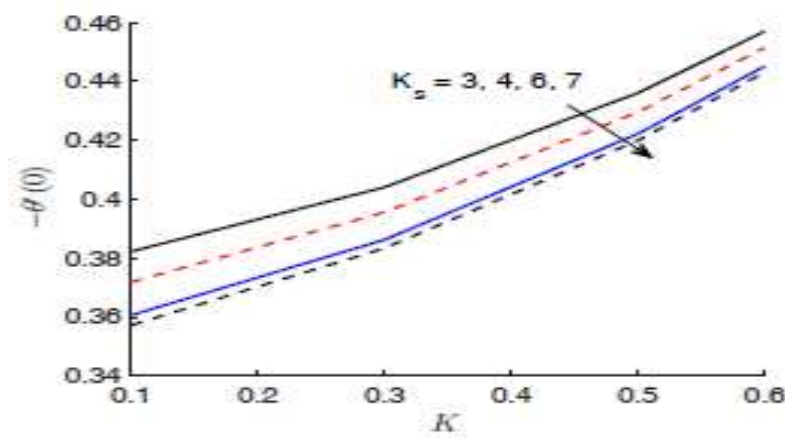

Figure 27. Effect of the homogeneous reaction parameter $(K)$ and the heterogeneous reaction parameter $\left(K_{S}\right)$ on the Nusselt number

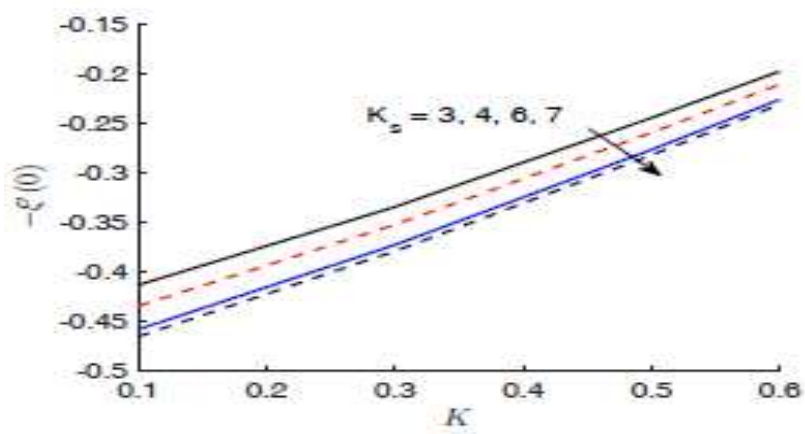

Figure 28. Effect of the heterogeneous reaction parameter $\left(K_{S}\right)$ and the homogeneous reaction parameter $(K)$ on the Sherwood number

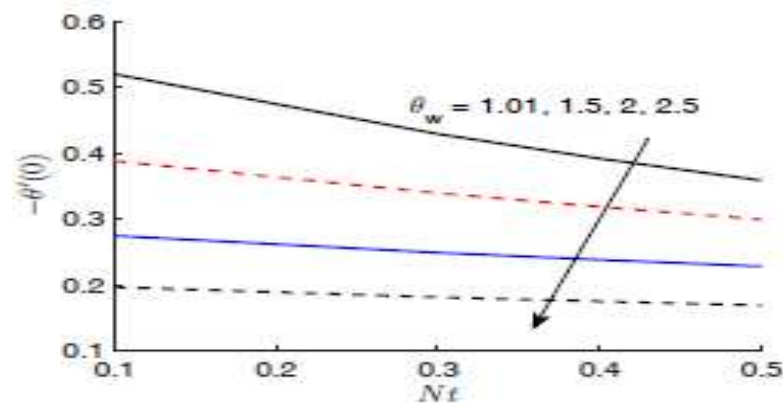

Figure 29. Effect of the temperature ratio parameter $\left(\theta_{w}\right)$ and the Thermophoresis parameter $(N t)$ on the Nusselt number

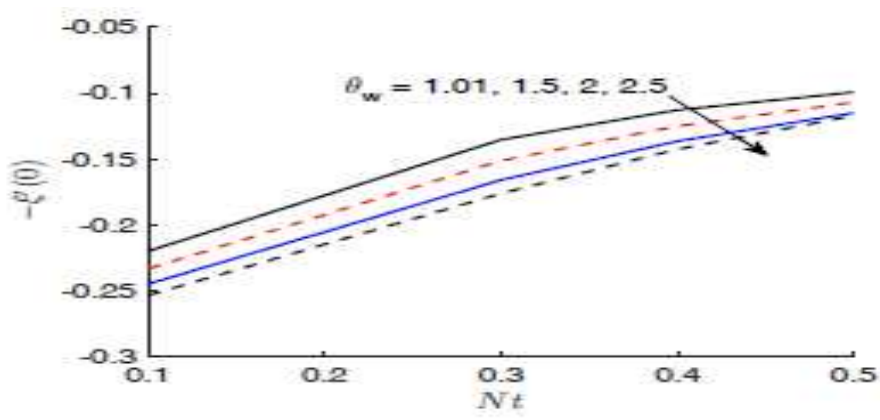

Figure 30. Effect of the temperature ratio parameter $\left(\theta_{w}\right)$ and the Thermophoresis parameter $(N t)$ on the Sherwood number 


\section{CONCLUDING REMARKS}

A numerical model is developed to study the entropy generation in MHD flow of viscoelastic nanofluids with homogeneous-heterogeneous reaction, partial slip and nonlinear thermal radiation. The resulting partial differential equations have been solved using the spectral quasi-linearization method (SQLM). The graphical results were obtained to illustrate the details of flow, heat and mass transfer characteristics and their dependence on some physical parameter. Following conclusions can be derived from the numerical results:

(i) Enhancement occur in thermal boundary layer, whereas the concentration and momentum boundary layer reduce when the viscoelastic parameter increases.

(ii) Velocity and concentration profiles are strongly influenced by the magnetic field in the momentum boundary layer, which decreases with the increase in the Hartmann number and reverse trends are seen for temperature profile.

(iii) Velocity and concentration profiles are reduced due to increase the partial slip parameter but reverse effects are seen for temperature profiles.

(iv) The Brownian motion parameter and thermophoresis parameter on temperature are similar, while the effects on nanoparticles volume fraction are opposite for increasing the Brownian motion parameter.

(v) The effect of nonlinear thermal radiation is to increase temperature in the thermal boundary layer.

(vi)The concentration at the surface decreased with the strengths of the homogeneous and heterogeneous reactions.

(vii) The Prandtl number and temperature ratio parameter show a quite opposite behavior for temperature and concentration profile.

(viii) The entropy generation number decreases with the increase of viscoelastic parameter and partial slip parameter, while the entropy generation number increases with the increase of Brinkman number and Reynolds number.

(ix) The Bejan number is strongly affected by variations in the viscoelastic parameter and dimensionless Brinkman groups.

$(x)$ The local Nusselt number and Sherwood number decrease with the increase in homogeneous and heterogeneous chemical reaction parameter.

\section{NOMENCLATURE}

\section{$A$}

$B$

$B_{0}$

$\mathrm{Br}$

C

$C_{a}$

$C_{b}$

$c_{p}$

$C_{w}$

$C_{\infty}$

$D_{A}$

$D_{B}$

$D_{T}$

$f$

$\mathrm{Ha}$

$h_{m}$

$h_{w}$

K

$K_{s}$

$k^{*}$

$k_{f}$

$k_{0}$

$N r$

$\mathrm{Nb}$

$N t$

$p$

$P r$

Re

$S_{g e n}^{\prime \prime}$

$S_{0}$

Sc

$q_{r}$
Homogeneous chemical reaction

Heterogeneous chemical reaction

Magnetic field strength $\left(\mathrm{kg} \mathrm{s}^{-2} \mathrm{~A}^{-1}\right)$

Brinkman number

Concentration $\left(\mathrm{kg} \mathrm{m}^{-3}\right)$

Concentration of homogeneous chemical reaction $\mathrm{A}\left(\mathrm{kg} \mathrm{m}^{-3}\right)$

Concentration of heterogeneous chemical reaction $\mathrm{B}\left(\mathrm{kg} \mathrm{m}^{-3}\right)$

Specific heat $\left(m^{2} s^{-2} K^{-1}\right)$

Concentration at surface $\left(\mathrm{kg} \mathrm{m}^{-3}\right)$

Ambient concentration $\left(\mathrm{kg} \mathrm{m}^{-3}\right)$

Diffusion coefficient of specie $A\left(\mathrm{~kg} \mathrm{~m}^{-1} \mathrm{~s}^{-1}\right)$

Diffusion coefficient of specie B $\left(\mathrm{kg} \mathrm{m}^{-1} \mathrm{~s}^{-1}\right)$

Thermophoretic diffusion coefficient $\left(\mathrm{kg} \mathrm{m}^{-1} \mathrm{~s}^{-1} \mathrm{~K}^{-1}\right)$

Dimensionless velocity

Hartmann number

Mass flux $\left(\mathrm{kg} \mathrm{m}^{-2} \mathrm{~s}^{-1}\right)$

Heat flux $\left(W m^{-2}\right)$

The stretch of the homogeneous reaction

The stretch of the heterogeneous reaction

Mean absorption coefficient

Thermal conductivity $\left(W m^{-1} K^{-1}\right)$

Material fluid parameter

Thermal radiation parameter

Brownian mention parameter

Thermophoresis parameter

Pressure $\left(\mathrm{kg} \mathrm{m}^{-1} \mathrm{~s}^{-2}\right)$

Prandtl number

Reynolds number

Volumetric entropy generation per unit length $\left(W m^{-4} K^{-1}\right)$

Dimensionless entropy generation rate

Schmidt number

Radiative heat flux $\left(\mathrm{kg} \mathrm{m}^{-2}\right)$ 


$\begin{array}{ll}T & \text { Temperature }(K) \\ T_{w} & \text { Uniform surface temperature }(K) \\ T_{\infty} & \text { Ambient temperature }(K) \\ U(x) & \text { Velocity of the stretching sheet }\left(\mathrm{m} \mathrm{s}^{-1}\right) \\ \Delta T & \text { Difference between }\left(T_{w}-T_{\infty}\right)(K) \\ \left(\rho c_{p}\right)_{s} & \text { Heat capacity of the nanoparticle } \\ & \\ \text { Greek Symbols } & \\ \alpha & \text { Viscoelastic parameter } \\ \alpha m & \text { Thermal diffusion of fluid }\left(\mathrm{m}^{-2} \mathrm{~s}^{-1}\right) \\ \varepsilon & \text { The ration diffusion coefficient } \\ \eta & \text { Dimensionless variable } \\ \theta & \text { Dimensionless temperature } \\ \theta_{w} & \text { Similarity variable related to the energy equation } \\ \lambda & \text { Dimensionless velocity slip parameter } \\ \mu & \text { Dynamic viscosity }\left(\mathrm{kg} \mathrm{m}^{-1} \mathrm{~s}^{-1}\right) \\ \nu & \text { Kinematic viscosity }\left(\mathrm{m}^{-2} \mathrm{~s}^{-1}\right) \\ \xi & \text { Dimensionless concentration of specie } A \\ \rho & \left.\text { Density of fluid (kg m } \mathrm{m}^{-3}\right) \\ \sigma & \text { Electrical conductivity }\left(\Omega^{-1} \mathrm{~m}^{-1}\right) \\ \sigma^{*} & \text { Steaffan-Boltzman constant } \\ \tau & \text { Ratio of nanoparticle heat capacity } \\ \tau_{w} & \text { Shear stress at the surface } \\ \phi & \text { Dimensionless concentration of specie } \\ \Sigma & \text { Dimensionless parameter } \\ \chi & \text { Constant parameter }\end{array}$

\section{REFERENCES}

[1] Choi SU, Eastman JA. Enhancing thermal conductivity of fluids with nanoparticles. Technical report, Argonne National Lab IL United States; 1995.

[2] Valyi EI. Extrusion of plastics. US Patent; 1992.

[3] Makinde OD, Aziz A. Boundary layer flow of a nanofluid past a stretching sheet with a convective boundary condition. Int J Thermal Sci 2011; 50 (7): 1326-32. https://doi.org/10.1016/j.ijthermalsci.2011.02.019.

[4] Chamkha AJ. MHD flow of a uniformly stretched vertical permeable surface in the presence of heat generation/absorption and a chemical reaction. Int Commun Heat and Mass Transf 2003; 30(3): 413-22. https://doi.org/10.1016/S0735-1933(03)00059-9.

[5] Putley E. The development of thermal imaging systems. Recent Advances in Medical Therm; 1984.

[6] Sandeep N, Sulochana C, Kumar BR. MHD boundary layer flow and heat transfer past a stretching/shrinking sheet in a nanofluid. Journal of Nanofluids 2015; 4(4): 512-17. https://doi.org/10.1166/jon.2014.1181.

[7] Sandeep N, Raju C, Sulochana C, Sugunamma V. Effects of aligned magnetic field and radiation on the flow of Ferrofluids over a flat plate with non-uniform heat source/sink. Int J Sci Engg 2015; 8(2): 151-58. https://doi.org/10.12777/ijse.8.2.151-158.

[8] Sheikholeslami M, Ganji DD, Javed MY, Ellahi R. Effect of thermal radiation on magnetohydrodynamics nanofluid flow and heat transfer by means of two-phase model. J Magnet Magn Mat 2015; 37(4), 36 - 43. https://doi.org/10.1016/j.jmmm.2014.08.021

[9] Hayat T, Muhammad T, Alsaedi A, Alhuthali M. Magnetohydrodynamic three-dimensional flow of Viscoelastic nanofluid in the presence of nonlinear thermal radiation. J Mag Magnetic Materials 2015; 385;222-29. https://doi.org/10.1016/j.jmmm.2015.02.046

[10] Animasaun I, Raju C, Sandeep N. Unequal diffusivities case of Homogeneous-Heterogeneous reactions within Viscoelastic fluid flow in the presence of induced magnetic-field and nonlinear thermal radiation. Alexandria Engg Journal 2016; 55(2):1595-06. https://doi.org/10.1016/j.aej.2016.01.018.

[11] Chaudhary M, Merkin J. Homogeneous-Heterogeneous reactions in boundary-layer flow: Effects of loss of reactant Mathematical and Computer Modelling 1996; 2 4(3);21-28. https://doi.org/10.1016/08957177(96)00097-0.

[12] Merkin J. A model for isothermal Homogeneous-Heterogeneous reactions in boundary-layer flow. Mathematical and Computer Modelling 1996; 24(8): 125-36. https://doi.org/10.1016/0169-5983(95)00015-6.

[13] Shaw, S, Kameswaran PK., Sibanda P. Homogeneous-Heterogeneous reactions in Micropolar fluid flow from a permeable stretching or shrinking sheet in a porous medium. Boundary Value Problems 2013; 1: 77. https://doi.org/10.1186/1687-2770-2013-77. 
[14] Goyal M, Bhargava R. Boundary layer flow and heat transfer of Viscoelastic nanofluids past a stretching sheet with partial slip conditions. Applied Nanoscience 2014; 4(6): 761-67.DOI: 10.1007/s13204-013-0254-5.

[15] Sheikh M, Abbas Z. Homogeneous-Heterogeneous reactions in stagnation point flow of Casson fluid due to a stretching /shrinking sheet with uniform suction and slip effects. Ain Shams Engg J 2015 . https://doi.org/10.1016/j.asej.2015.09.010

[16] Bachok N, Ishak A, Pop I. On the stagnation-point flow towards a stretching sheet with HomogeneousHeteregeneous reactions effects. Commu Non Sci Numerical Simu 2011; 16(11): 4296-02. https://doi.org/10.1016/j.cnsns.2011.01.008.

[17] Hayat T, Imtiaz M, Alsaedi A. Effects of Homogeneous-Heterogeneous reactions in flow of Powell-Eyring fluid. Journal of Central South University 2015; 22: 3211-16. https://doi.org/10.1007/s00521-017-2943-6.

[18] Mirzazadeh M, Shafaei A, Rashidi F. Entropy analysis for non-linear Viscoelastic fluid in concentric rotating cylinders. Int J Thermal Sci 2008; 47(12): 1701-11. https://doi.org/10.1016/j.ijthermalsci.2007.11.002.

[19] Aiboud S, Saouli S. Entropy analysis for Viscoelastic magnetohydrodynamic flow over a stretching surface. Int. Jf Non-Linear Mechanics 2010; 45(5): 482-89. https://doi.org/10.1016/j.ijnonlinmec.2010.01.007.

[20] Mishra S, Mondal H, Kundu PK, Sibanda P. Unsteady MHD micropolar fluid in a stretching sheet over an inclined plate with the effect of non-linear thermal radiation and soret-dufour. Journal of Thermal Engineering 2019; 5(6):205-13. https://doi.org/10.18186/thermal.654344.

[21] Chaudhary M, Merkin JA. Simple isothermal model for Homogeneous-Heterogeneous reactions in boundary layer flow. I Equal Diffusivities Fluid Dynamics Research 1995; 16(6): 311-33. https://doi.org/10.1016/01695983(95)90813-H.

[22] Awad MM. A review of entropy generation in microchannels. Advances in Mechanical Engineering 2015; 7(12): https://doi.org/10.1177/1687814015590297.

[23] Bejan A. Advanced engineering thermodynamics. John Wiley \& Sons; 2016.

[24] Awad MM. A new definition of Bejan number. Thermal Science 2012; 16(4): 1251-5. https://doi.org/10.2298/TSCI12041251A

[25] Awad MM, Lage JL. Extending the Bejan number to a general form. Thermal Science 2013; 17(2): 613-33. https://doi.org /10.2298/tsci130211032a.

[26] Awad MM. Hagen number versus Bejan number. Thermal Science 2013; 17(4): 1245-50. https://doi.org/10.229 8/TSCI1304245A.

[27] Awad MM. An alternative form of the Darcy equation. Thermal Science 2014; 18(2): 617-19. https://doi.org/10. 2298/TSCI131213042A

[28] Awad MM. The science and the history of the two Bejan numbers. Int J Heat and Mass Transfer 2016; 94: 10103. https://doi.org/10.1016/j.ijheatmasstransfer.2015.11.073.

[29] Motsa S, Sibanda P, Shateyi S. On a new quasi-linearization method for systems of nonlinear boundary value problems. Mathematical Methods in the Applied Sciences 2011; 34(11): 1406-13. https://doi.org/10.1002/mma. 1449

[30] Almakki M, Dey S, Mondal S, Sibanda P. On unsteady three-dimensional axisymmetric MHD nanofluid flow with entropy generation and thermo-diffusion effects. Entropy 2017; 19(7): 168. https://doi.org/10.3390/e19070 168.

[31] Chand R, Rana G, Hussein A. On the onsetof thermal instability in a low Prandtl number nanofluid layer in a porous medium. Journal of Applied Fluid Mechanics 2015; 8(2): 265-272. https://doi.org/10.18869/acadpub.jaf m.67.221.22830.

[32] Al-Rashed AA, Kolsi L, Hussein AK, Hassen W, Aichouni M, Borjini MN. Numerical study of three dimensional natural convection and entropy generation in a cubical cavity with partially active vertical walls. Case Studies in Thermal Engineering 10, 100-110 (2017). https://doi.org/10.1016/j.csite.2017.05.003.

[33] Kolsi L, Hussein AK, Borjini MN, Mohammed H, Aïssia HB. Computational analysis of three-dimensional unsteady natural convection and entropy generation in a cubical enclosure filled with Water- Al2O3 nanofluid. Arabian Journal for Science and Engineering 2014; 39(11): 7483-93. https://doi.org/10.1080/104077782.2016. 1173478 .

[34] Chand R, Rana G, Hussein A. Effect of suspended particles on the onset of thermal convection in a nanofluid layer for more realistic boundary conditions. Transport in Porous Media 2010; 83(2):425-36; https://doi/10.100 7/s11242-009-9452-8.

[35] Mallikarjuna B, Rashad A, Hussein A, Hariprasad Raju S. Transpiration and thermophoresis effects on NonDarcy convective flow past a rotating cone with thermal radiation. Arabian Journal for Science \& Engineering 2016; 41(11): 4691-700. https://doi/10.1007/s13369-016-2252-x. 